\title{
Tales of suffering and strength: women's experiences of working in Nepal's informal entertainment industry
}

\section{Tamsin Bradley* and Sutirtha Sahariah}

School of Languages and Area Studies,

University of Portsmouth, UK

Email: tamsin.bradley@port.ac.uk

Email: suti011@gmail.com

*Corresponding author

\begin{abstract}
This article gives a deep insight into the experiences of women working in Nepal's growing informal entertainment industry. It documents past experiences of extreme violence as a result of the Maoist insurgency and at home in the form of child abuse, IPV and other forms of domestic violence. It records how these past traumas drove the women to seek new violent-free lives in Kathmandu where the informal entertainment industry offered the best source of income. Despite horrific tales of ongoing harassment from clients, the women talk of the relief they feel at being able to earn an income that can support their children. They talk about increased self-confidence that they link to their ability to earn a good income. The women also shared their coping strategies, the support they gained through peer networks and through a vital local organisation clearly represents critical dimensions in strengthening their resilience to violence.
\end{abstract}

Keywords: women; Nepal; violence; entertainment sector; income; sex work.

Reference to this paper should be made as follows: Bradley, T. and Sahariah, S. (2019) 'Tales of suffering and strength: women's experiences of working in Nepal's informal entertainment industry', Int. J. Gender Studies in Developing Societies, Vol. 3, No. 1, pp.20-36.

Biographical notes: Tamsin Bradley is a Professor of International Development Studies at the University of Portsmouth. She has conducted research exploring the interfaces between gender, religion and development in India, Nepal, Myanmar, Pakistan, Tanzania, Nigeria, Rwanda and Sierra Leone. She is currently working on a global comparative study of harmful cultural practices including dowry and FGM. The study considers the impact of migration, economic liberalisation and globalisation on the prevalence rates of these practices and the ways in which they are observed. This study forms part of her wider research portfolio on gender-based violence.

Sutirtha Sahariah is a $\mathrm{PhD}$ researcher and journalist. He has published widely on issues to do with violence against women and girls in South Asia.

\section{Introduction}

This article presents in-depth insights into the complexities and often contradictions in how women working in Nepal's informal entertainment sector experiences both violence 
and earning an income. In particular, we were keen to explore if income allows women to build greater resilience to forms of violence feeling more empowered to exercise agency around a range of issues from how to spend their money to challenging the abuses that their peers suffer. Central then to our theoretical inquiry is an exploration into what agency, resilience and empowerment actually mean in the lives of women who arguably work in a sector already seen as a harmful and vulnerable environment for women. Kabeer (2003) is known for defining empowerment in terms of agency to make choices and be able to negotiate a better life challenging injustice when it occurs. Access to sufficient recourses is key but it is also depends on an environment that is supportive and respects the need for positive working conditions and fair wages. Lastly, empowerment can be seen in terms of positive actions enabled because of strong agency and resource capacity. We know that economic engagement alone cannot produce a magic bullet; in fact, it can often have disempowering affects (Kabeer, 2012). The market discriminates in wage rates and hiring practices for example with women only being able to access unskilled and low paid work (Anker et al., 2003). This details the realities of the working environment for the women we spoke with who have been pushed into an unregulated and marginal sector that many authorities would rather not acknowledge exists. This is ironic given that state actors such as the police and politicians are often the primary clients. A key question explored in much literature then is why are women drawn to this sector and are they still able to exercise agency and control of decision making?

In this article, we will apply Kabeer's model adapting it to the specific experiences of the women we spoke with. In doing so, we also apply two other frame works; the social ecology framework endorsed by numerous development institutions, including DFID (2012). It presents a picture of violence as inherently multifaceted, produced by the interaction of numerous elements of everyday life at various levels (e.g., household, community, nation). Its focus on the 'embedded' nature of violence is extremely important, as it highlights the fact that structural changes (such as legal reform) and even community-level interventions are unlikely to achieve dramatic transformation unless efforts are also made to work on and within the broader cultural systems in which they are located, interpreted and enacted. An intersectional approach recognises that gender is by no means an isolated social category. Rather, it acts to constrain women's freedoms in diverse ways by interlinking with additional categories such as race, caste, class, disability, sexual orientation and age, which contribute further to social, economic and political power inequities. The aim then is to analyse the "differential ways in which social divisions are concretely enmeshed and constructed by each other and how they relate to political and subjective constructions of identities" [Yuval-Davis, (2006), p.205].

The story we unfold in our data analysis highlights how female entertainment workers regard earning an income. The importance of income for their sense of well-being and agency is explored. The data also allows us to see a wider more complex picture picking up other dimensions that need to be in place in order to drive greater gender equality. In particular we have found that local women's organisations and/or mobilisers trained to end violence are critical in bridging the gap between income and increased resilience to violence. The picture is of course nonlinear, with women recording, according to global definitions, many forms of violence whilst not always regarding them as such. The normalisation of violence remains deep rooted even in cases where intimate partner violence is experienced daily. The women we spoke with who work in the entertainment sector have histories of extreme violence both at home but also, in Nepal, in the hand of 
the Maoist insurgents. These past traumatic experiences of abuse are what has driven them out or rural areas and into Kathmandu's growing informal entertainment sector. Understanding how and where income can feed into a process of positive change is vital if we are to construct a holistic and workable approach to end violence against women.

This article presents new evidence into the diversity of violence experienced by female entertainment workers, it also captures the various ways income impacts on women's lives and finally it highlights the role that women's networks and organisations play in bridging gaps between income and resilience to violence. The picture is complex and as the title suggest contradictory. Despite past and ongoing daily experiences of violence the women interviewed value the work their do and link it to raised self-esteem and autonomy.

This research is based on 30 in-depth interviews with women working in the informal entertainment industry, primarily the dance bars and massage parlours of Thamel in Kathmandu. The interviews were conducted in the safe space provided by Raksha Nepal and with staff present in case psychological support was needed. The women are part of a wider network and are linked with more than one NGOs. Raksha Nepal and three other organisations mentioned in the article below are all members of Campaign for Right Alliance. However, Raksha Nepal's assistance was taken due to proximity to Thamel where most women work and also their office provided safe and premises for conducing the interviews. Most of the women were now living on their own with children (although in most cases the children were either in private boarding schools or if girls are being cared for by Raksha Nepal). The women came from a range of caste and ethnic groupings from Dalit to Brahmin. Educational levels were very low with most women not excelling beyond grades 5-7. All the women interviewed had migrated from rural districts driven from home by domestic violence, violence at the hands of Maoist and/or the poverty left by the earthquake (or a combination of all). The research was conducted in accordance to strict protocols reviewed and in line with the WHO guidelines.

The article is structured as follows: Section 2 reviews the international literature on women's experiences of working in the formal entertainment sector and in particular looks at what has been researched in regard to Nepal. Section 3 presents the key findings and offers two in-depth and representative case studies of women who work or have recently worked in the Thamel entertainment district. Section 4 will offer a brief summary of the work of the organisations in Kathmandu positioned to support women in the entertainment sector whose role in the lives of many women's lives is evidenced as critical in supporting the increase in agency and self-esteem despite violence. Section 5 reflects on the importance of peer networks and specialist support organisations in addition to income in order for women to feel empowered to lead autonomous lives.

\section{What does the literature tell us about women's experiences in the entertainment sector?}

'Sex worker' and 'entertainment workers' are labels that are used interchangeably. In this paper we are using the term 'entertainment' rather than 'sex' or 'prostitution' for two reasons. First, this is how the women themselves label their occupation mainly to reflect the broad range of services they provide which does not just or always include sex. Secondly, prostitution is illegal in Nepal and whilst most of the women's clients were politicians and policemen it is necessary for the women to maintain as much invisibility 
around this area of their work. Theories of prostitution in the Euro-American context have examined sex work broadly from two paradigms: empowerment and oppressive paradigms (Weitzer, 2010). The proponents of the oppressive paradigm emphasise that sex work is a typical expression of patriarchy and gender relations. They go on to say that exploitation, subjugation and violence against women are intrinsic and ineradicable from sex work (Dworking, 1981; Jeffreys, 1997; MacKinnon, 1989).

The oppressive paradigm points out that sex work is essentially denigrating as it facilitates men to pay and thereby control the sexual labour of a women. This transactional exchange subjugates a woman sexually and emotionally (O'Connell Davidson, 2002). Such acts reinforce the social construction of women as object of sex and socially inferior to men. However, the scope of study for sex industry is no longer restricted to brothels alone. Sex work includes exotic dancing, prostitution and other exchanges of sex for money, such as sometimes occur in massage parlours and escort services. Studying exotic dancing as a form of sex work is important because it not only makes up a large and lucrative part of the sex industry, but it is also increasing in its scope.

The proponents of the empowerment paradigm emphasise sex work as a labour where a woman detaches herself from her sexuality and offers her services purely on a commercial basis. The argument states that in doing so, she has the power to contain her emotions. Chapkis (1997) emphasises that it is not the commodification of emotion per se that is problematic in sex work; rather: "mundane concerns like status differences between worker and client, employee/employer relations and negative cultural attitudes toward the work performed, may be at the root of the distress and damage experienced by some workers". Dudash (1997, p.25), for example, argues that working in the sex industry can be empowering for women in that they acquire a sense of being in control of their own bodies and are thus able to deal more effectively with the harassment associated with sex work. Similarly, Chapkis (1997) in Live Sex Acts: Women Performing Erotic Labour argues in favour of commercial sex being defined as 'erotic labour'. Such arguments hold true if a sex worker is operating in a 'safe' environment and there are mechanisms in place to deal with errand and violent clients. Studies (Deshotels and Forsyth, 2006) show that erotic dancers use 'strategic flirting' or 'false kindness' (Eaves, 2002) to induce customers to give them money and at times they tend to control their clients emotionally and as a result feel a sense of empowerment.

Such studies inform the theory of 'power for women'. 'Strategic flirting' subverts gendered power relations in that women are dominant and the men subordinate. However, critics of such theory like woods [as cited by Deshotels and Forsyth (2006, p.236)] argue that women play a subordinate role where she must satisfy a man and do things he wants and "in many ways she is manipulating her emotions for the satisfactions of the customers". Barton (2005) as cited by Deshotels and Forsyth, (2006), found that whilst women may find some aspect of their emotional labour satisfying (like customers accepting their advancements or their ability to play with the customers) dealing with rude and difficult customers can adversely affect them. In this way, Barton (2002) asserts that whether they feel empowered is dependent on customer reaction.

Boyle (2010) as cited by Coy et al. (2011) is critical of the manner in which women in the sex and entertainment industry are glamorised by the media in their efforts to shape popular culture. He uses the term 'superficial empowerment' to describe any sense of power and control women in the sex industry may feel. He goes on to state that media 
narratives are too often built around a perception that women have the freedom' to self-sexualise and there is a tendency to commodify their bodies in the market. Jenkins (1992) refers to this as "holistically framed as sexualised and pornified popular culture", where 'sex work has been glamourised and normalised through media narratives that have absorbed it into particular projections of popular culture. This in turn has a negative disempowering impact as it legitimised the commodification and objectification of women's sexualised bodies even further.

For context, research demonstrates that the majority of women in the sex industry report experiences of physical and sexual violence - one study of 854 people in nine countries found that $63 \%$ had been raped since entering prostitution, suggesting that violence is a routine rather than exceptional event (Farley et al., 2003). Violence and abuse are not confined to specific settings - a quarter $(23.3 \%)$ of exotic dancers, and over two thirds $(66.7 \%)$ of women in prostitution in US drug houses reported sexual violence, while one in five (21\%) of women in prostitution on the street, in their own homes and as escorts had been raped more than ten times (Raphael and Shapiro, 2004). A UK study across three cities found almost half of women in street prostitution and over a quarter of those in indoor prostitution had experienced violence in the last six months (Church et al., 2001). Qualitative analysis of women's accounts of prostitution illustrates parallels with their experiences of sexual violence in terms of their sense of violation and disruption of relationship with the body (Coy, 2009).

The empowerment and oppressive paradigms discussed above are based on the examination of the sex industry in the developed world where the remuneration from such work is reasonable and there are adequate mechanisms in place for the safety and security of women engaged in various kinds of entertainment and sex work. Critics of such studies say contemporary Euro-American feminist debates on prostitution simply lack reference to "the basic concepts of class and social relations of production" that lie at the heart of why women work in the sex industry [Aguilar (2000) cited by O'Connell Davidson (2002, p.93)]. Certainly, the questions about prostitution that preoccupy many Euro-American feminists can seem irrelevant in the developing world where many women are pushed into or forced to join the informal sex industry due to poverty, survival needs, conflict and various forms of gender-based violence and discrimination that are ingrained in the social fabric of societies around the world. Also, the empowerment paradigm does not analyse the broader debates of migration and the trigger causes behind a woman's decision to work in the informal entertainment sector. In particular, such studies do not question the 'income' factor as an independent variable and driver in it behind women's decision to work in this sector. Studies on women's economic empowerment reveal that income is a way of not just surviving physically but also a means to enhance voice and agency in their domestic and personal sphere (Klugman et al., 2014). A critical question largely unanswered in the context of sex work in the developing world is to what extent income earning through entertainment is experienced as empowering?

The research in this article then attempts to gain something of a deep understanding into the motivations of the women who work in the entertainment sector and specifically the choices they have made to do this work rather than to enter construction or domestic service, two other options available to them. As stated in the introduction, we will consider the empowering aspect of earning an income in this sector by applying Kabeer's empowerment model which can be summarised as: agency-resource-actions. 
While there is a tendency amongst the feminists from South Asia to look at the lives of sex workers through a 'misery' lens, Murthy and Seshu (2013) argue sex workers may have a sad story to tell but they do not get 'frozen in sadness'. They argue that several tenets of patriarchy are challenged within sex work not least because women's decisions making power is significantly increased at home giving them a sense of control and independence otherwise denied. They point out whilst there has been a large body of writing on sexuality, labour and trafficking, there is comparatively little on sex as work or the business of sex. They stress that there is a greater need to understand sex work from the perspective of sex workers in order to gain deep insight into the possible empowering or not impact it brings. We argue that unravelling these difficult questions can be helped by both listening to the experiences and stories of women entertainment workers directly and through the application of Kabeer's model. Does the income earned represent sufficient a resource for them to be able to leverage confidence to act to bring about other change?

A further critical question remains to what extent should sex work be seen as a form of violence against women? While there is a consensus that violence is inherent in sex work and that it commodifies a woman's body by bringing them to the marketplace to be exploited by men, there is, however, a greater need to look at the sex industry and its allied activities like (dance bars, exotic dancing, escorts and cabin restaurant) from a broader social, economic and political perspective. This is necessary because as sex work is largely shaped by global and regional socio-cultural contexts but yet understanding of this is somewhat limited (Busza, 2004; O’Connell Davidson, 2006).

Ditmore (2014) as cited by Monto (2014) while examining the lives of women engaged in the informal sex industry in Cambodia states that they suffer varied and extreme violence (Farley et al., 2003). However, interestingly she stops short of calling the industry violent as women engaged in the industry do not want it to be abolished. They demand better working conditions free from harassment, violence and exploitation by pimps, businesses, police, and other actors. Despite limited choices of alternate employment and despite their marginalisation and exclusion, many prostitutes interviewed by Ditmore work to uphold culturally valued social obligations such as paying off debts and supporting their families (Monto, 2014). The sex industry then offers a lucrative means of earning an income that can in turn support families. The question then arises, if other lucrative earning options existed would women still choose to work in the sex industry?

Recent efforts to address the harm associated with prostitution (O'Connor and Healy, 2006), as well as less recent feminist theory (MacKinnon, 1987, 1993; Dworkin, 1993, 2004), have gone so far as to define prostitution as violence against women. Such pronouncements obscure a more complex relationship between the sex industry and different forms of gendered violence (Weitzer, 2005). Monto (2014, p.77, p.78) who reviews four studies on Cambodia asserts that the role of violence, the forms it takes, and its likelihood differ dramatically from context to context. She argues that defining prostitution as violence results in "a tautology in which the cause, the effect, and the definition of violence are all conflated". He asks, "how often is violence or the fear of violence a motive for entering or participating in prostitution? Is violence in the sex industry related to violence against women more generally? If prostitution is violence, important questions such as these become irrelevant". In the context of the women we have spoken with, the violence represented through their profession must be seen 
relatively to the extreme violence they have suffered in the past in most case leading to their decision to work in entertainment. The position of women in Nepalese society has been traditionally weak because of dominant patriarchal systems. The harmful cultural practices like child marriage, dowry and lack of education tend to further disempowered women and expose them to violence (Basu and Dutta, 2009). Also, years of internal conflict between Maoists and government forces have displaced thousands and propelled internal migration and many women and girls have landed up in highly exploitative environments including commercial sex work in order to meet their survival needs [Youth Partnership Project (YPP) (2010) as cited by Kaufman et al. (2016). However, as the stories below attest, the exploitation of the industry leave less of a traumatic imprint that the oppressive and abuse of their past.

In the context of Nepal, Liechty (2005) highlights how Kathmandu emerged as a hub for prostitution and male entertainment in the early 1990. Globalisation has resulted in the emergence of 'restaurants of dance' potent symbols of a new modern culture. The new zones of entertainment become the hotspot where bodies lose their caste-based moral meanings and become anonymous parts of a 'free market' of commercial exchange. Thamel in that context allows women a certain sense of anonymity within the boundaries of a highly commercialised sphere (Liechty, 2005, 2010 as cited by Caviglia, 2017). As stated from the start the application of Kabeer's model allows us to focus on the question of agency and resilience and ask if empowerment can be seen through the access to income the women now have.

Basnyat and Joyti Dutta (2012, p.1045) ask similar questions arguing that women in this sector are not agency-less but rather negotiate within the marginal space they find themselves. We argued in the later sections of this article that the room to bargain and express resilience is supported by an enabling environment and strong peer ties that serves to bolster individual agency and drives collective action.

Follow this concise review of global literature we will now turn to present the stories and experiences collected through our fieldwork in Thamel, Kathmandu's main entertainment hub. In particular, we will consider how and if our data departs from the accounts and arguments main above.

\section{Women's voices from Nepal's informal entertainment sector}

All the women we spoke with had suffered very extreme forms of violence either sustained beatings from family members (pre-migration) or from husband's pre and post migration including marital rape. Some of the women we spoke with had been kidnapped by Maoist rebels and sustained a period of ongoing sexual torture. The psychological trauma endured by all the participants was considerable. Concepts of Izzat or honour also operated to keep women locked in violent relationships, to leave would result in bringing shame on parents and in-laws. For the women we spoke with, because of codes of Izzat, once they had left their marital home they could no longer have contact with either their parents or in-laws. Despite being cut off from relatives on both sides, leaving behind abusive husbands and family members was a positive turning point for most of the women even despite their daily hardships. For all the women the entertainment sector offered their best option of an income high enough to look after their children and secure a roof. 
Even despite the means of income generation all the women talked about the importance of earning their own money and the level of self-esteem they got from being able to provide for their children. They all talked about their desire to set up their own business and learn new skills to lead into different work. However, they were also clear that they would remain working in the entertainment sector until they had secured enough funds to set up their own business. All the women suffered very high levels of violence at work and therefore felt very unsafe at work. That said, and when asked how they coped with this a common response was "we have each other, we work together to ensure we are safe." All felt that contact with an organisation such as Raksha Nepal had increased their confidence and helped them process the violence they had and continued to suffer. For example; "without organisations like Raksha Nepal I know I would have sunk into a deep depression and that what would have happened to my children?"

The women talked about the ineffectiveness of the police if they reported an assault at work or at home. The police made up a significant number of their clients yet raids and arrests were frequent and an ongoing cause for anxiety. This reality makes improving the women's safety a challenge; if the justice providers are in fact the main clients the road to social change will be slow.

The caste or educational background made no difference to the levels of violence suffered or the ability of the participant to mitigate it. All the women recognised the importance of saving earnings but not all of them were able to do so. A significant number of women mentioned problems with getting citizenship status for their children and this was a source of anxiety. When asked; would you do this work if you had a choice; the women commonly replied "yes, I have autonomy and a freedom I have never experienced before. Whilst we still face violence it is not on the scale of past suffering". This is a key point, the violence in many of the women's past was so extreme they talked about their relief that is was behind them. They seemed therefore to have resilience to the ongoing daily harassment because of what they had ensured. Many women talked about how leaving their husbands were such a pivotal point in their lives, as one woman stated she felt 'truly empowered'.

The two case studies below share very similar experiences to all the women in our sample. Presenting their stories in a fuller summary enables a more in-depth view to emerge supporting many of the findings detailed above.

\section{Case Study 1}

"I was married in April 1990. I was fourteen and was studying standard 10. I come from a Brahmin family. My father is a priest and commands a lot of respect. My husband had proposed marriage to me to my father. He was reluctant for a number of reasons: I was too young and still going to school. We were upper caste and the boy was known to be of bad character, but he put pressure on my father and threatened to kidnap me. My father married me off taking into consideration his family reputation and prestige (Izzat).

My husband started beating me only weeks after our marriage. It became more frequent and server (sometimes he would thrash me with a table). He would usually beat me up when drunk. No one came to protect me including my husband's parents, four brothers and two sisters. 
I was still studying. I would wake up at dawn and cook food for the entire family. In our culture the daughter-in-law is not expected to eat food before serving her husband's family so I used to go to school on an empty stomach. If I would eat food before serving my in- laws, they would not eat.

My in-laws expected me to do all the housework and was not happy with my going to school. Eight months into our married my in-laws asked my husband and me to leave because they no longer wanted to witness his beatings.

Whilst I was studying so was my husband. We used to make money by selling rice. We moved to Kathmandu in December 1990 we didn't know anyone except a cousin. We stayed in Dharmsala and then my cousin found a place on the outskirts of the city near the airport. My husband had no money, so the cousin paid the rent.

Meanwhile, I became pregnant and at the very advanced stage of my pregnancy my husband kicked me very hard and beat me ruthlessly. I came to know that day he remarried someone else. So, after a few days delivery came I was alone in the hospital, I gave birth to a dead child. The doctors thought it was due to my husband beating me.

I had to restart my life. I started working in a candy factory. My job was to wrap candies. I earned 40 rupees a day and rented a room for 1,200 rupees. I lived like this for 3 years until I was seventeen. Then my husband returned one day and pleaded for us to live together again. He was sorry for what he did and promised he would be a good man. I became pregnant again and gave birth to a baby boy in 1994 . The beatings resumed in June 1995. I was sent home to be with the in-laws and help with the farming. In 2001 my husband returned, and I became pregnant again.

I stayed with him because of the Izzat of my father and in-laws. I had nowhere to go and I thought life would be harder for my children without a father. Poverty though hit hard so I returned to Kathmandu in search of work. I stayed with my sister-in-law but she didn't give us any food. I used to cycle 20 kilometres a day selling vegetables, but business was bad. Then a friend told me about sex work. Purely out of desperation I worked as a contract sex worker for a year and I am not ashamed of it. I couldn't let my children starve. I made 3,000 rupees a day and slept in an average with three men a day. Some customers were violent they beat me and didn't pay me. Police harassment was huge.

After one year, I had earned enough to start a new business. I used to import clothes from the Indian border and sell them. I made around 15000 rupees a year. I did occasional contract sex work and lived like this for about 5 years.

In 2009 a friend told me about Raksha Nepal and their cooperative. The chairperson asked about my life and then introduced me to the savings scheme. I took out a loan and open my own restaurant bar in Thamel. The business did well, and I paid off my loan and then opened a guest house. Today I employ 7 women and will buy another guest house.

Today my children are doing well. The eldest is studying engineering, the second son management and my daughter is in school and they want to be lawyers". 


\section{Case Study 2}

The second example case study is 51 and no longer living with her husband. She has six children four sons $(35,31,37,28)$ two daughters $(29,26)$. She is Hindu and from the Chettri caste. She was 11 when she got married her husband was 27 . They lived in Dholaka village. Her grandparents believed in marrying daughters before mensuration. She first got pregnant at 13 but miscarried. Her husband left her and remarried when her youngest child was 6 months. She moved to Kathmandu 24 years ago. Before that her husband worked in the police in capital whilst she remained in the village living with in-laws and working in the fields.

When asked if her in-laws treated her well she replied "no because I did not bring in any dowry, so they beat me regularly. It wasn't a caste problem it was because I was poor. My husband used to come home once a year during festival. He was having an affair in Kathmandu".

Her husband called her to Kathmandu but soon after helost his job. So she had to work as a domestic servant where she earned very less, and then seeing her pitiable condition, a person known to her husband introduced her to the entertainment sector. She says as a domestic servant she earned 2,000 rupees a month but as a sex worker she earned 5,000 rupees. To begin with she only slept with one man a day but by the end it was five. She described her situation; "I had a lot of problems. I was bleeding. I wasn't aware about condoms. Some men were violent". Her employees said that her husband was beating her up so at least in sex work she was earning a living. She worked in the entertainment sector for ten years and then finally left using her savings to set up a small tea shop. Later she worked for a NGO WATCH as a field worker.

When asked why women face violence she replies, "it's because we aren't educated. I think women are strong and they should speak out and not allow men to dominate". She also went on to state, "leaving my husband was an important point in my life. I finally felt free and could make decisions on my own and for my children. Whatever I suffer now I can put up with, I just remember how bad it used to be and how desperate I felt. Earning my own money gives me confidence and makes me feel that anything is possible".

Applying our various theoretical models outlined at the start and in relation to Kabeer's empowerment model, clearly the women all experienced greater agency as a result of their work in the form of decision making and this is described as liberating. The psychological benefits are clear however clear actions of resilience require far more than just control over decision making in regard to income. Perhaps, due to the marginality of their work peer networks take on a hyper importance. However, to be effective the enabling environment needs to be solid. In Kathmandu as number of organisations have sprung up operated by women who themselves worked in the sector. A map of this organisation and the motivation of these that lead them are given in the next section. Here it is important to note that intersectionally violence and marginalisation cuts across caste and ethnic status. The major determining factor in driving women into this sector is poverty and past experiences of violence. Applying the ecological model to the microcosm the represents the informal entertainment sector different social structures emerge. 
- $\quad$ single woman living alone with children

- $\quad$ peer network

- $\quad$ outer circle of support organisations and trade unions

- a donor community sympathetic to putting resource into support organisations.

These dimensions then exist inside a meta-environment that is hostile populated by a police and people in authority that on the one hand shuns women who work in the sector whilst also seeking their services. Resilience in the context of entertainment work should be measured in relation to the robustness of the microcosm build around the women.

\section{Mapping the enabling environment - the importance of role models}

For the purpose of this study, scoping work was done to map out the organisations that work with women in the informal entertainment industry. Four organisations Raksha Nepal, Jagriti Mahila Maha Sangh (JMMS), Society for Women Awareness in Nepal (SWAN), Biswas Nepal were considered as they are specifically lead by women, who themselves worked in the informal entertainment industry. Accordingly, in-depth interviews were conducted to understand the factors that enabled them to move out of the sector, and set up NGOs that work for the welfare and protection of rights of women engaged in the sector.

The leaders of these organisations. Menuka Thapa of Raksha Nepal, Bijaya Dhakal of JMMS, Shova Dangal of SWAN and Tara Bhandari and Balkumari Ale of Biswas Nepal as a result of their unique position and experience have a first-hand understanding of complexities of problems and challenges that women in this sector face. This knowledge helps them to efficiently relate to, connect with and mobilise women who work in this sector.

The leadership of these women are increasingly being recognised by stakeholders and they have become activist voices for women working in this sector. Their organisations play an instrumental role in executing campaigns and programmes funded by international donor agencies in areas of HIV prevention, use of condoms, vocational trainings, health and safety awareness and prevention of trafficking of girl children into the informal entertainment industry. They have also federated into national networks and formed unions and saving and credit schemes and at large campaigning with the government to demand better working conditions for the women working in this sector.

The emergence of these women as community leaders can be seen in the context of positive deviance. Positive deviance is seen as a social inquiry which is based on the premise that in every community there are certain individuals or groups whose uncommon behaviour and strategies enable them to find better solutions to the same problems facing their peers (Friedman et al., 2017). Positive deviance involves identifying "champions" for change who have demonstrated resilience and exceptional outcomes against high risk situations. The factors that drive their actions and behaviour is worth replicating in designing programme and interventions with an aim to effect a change in respect to a targeted group or community (Friedman et al., 2017; Marsh et al., 2004). 
All four leaders contend that they have been direct beneficiaries of programmes that were rolled out 2000-2005. These programmes were funded by international donors in order to combat HIV/AIDS epidemic amongst high risk groups. They talked of their experiences working within these programmes as highly empowering giving them a sense of identity and an alternative perspective on how they might build a better life. They were initially recruited by the donor organisations running these early programmes as outreach workers. They were recruited because they demonstrated exceptional leadership qualities, a fighting spirit, and determination to change and were viewed as excellent motivators.

Tara Bhandari and Balkumari Ale attended a training programme funded by ILO and facilitated by NGO Maiti Nepal that works to prevent trafficking and forced prostitution. "They taught us things like "who am I', about problem solving and stress management. It helped us recognise our strength and capabilities".

They went on to share; "We felt that we were reborn. Earlier we were so ashamed of our work. We almost lead a secretive life. The society looked down upon us. After the training we felt motivated and realised they we too have self-respect and dignity. We had completed school so able to grasp things, so we started motivating others and imparting basic literacy skills to other women working in the bars, restaurants and cabins for a year".

Given their persistence to bring about decisive change in the lives of women engaged in the entertainment industry they were encouraged by Maiti Nepal to set up their own organisation aided by international donors. "The donors see us a very capable change makers because we are from the industry, have lived through the experience and we are also hard-working and committed and their objectives are aligned with our goals".

Vijaya Dhakal, the president of JMMS, worked as sex worker after her husband's sudden death. For a while, she worked in a garment factory, but income was never enough to feed her extended family. When General Welfare Pratisthan (GWP), an implementing organisation came to her village to promote safe sex, condom use and risk reduction strategies amongst sex workers. They started looking for someone from the sex worker community who could motivate others. Dhakal says from the very beginning she took active interest in training and advocacy programmes. The association with the NGO helped her to understand the importance of a collective voice and she felt there was a chance to make a difference to the lives of women like her. She was recruited by GWP and given a leadership role; "I was selected because I was very vocal. I would easily that I am a sex worker which no would dare to say in villages even today. I learnt that if you hide your identity you don't get your rights".

JMMS which was formed in 2011 is today a federation of 27 NGOs working in 21 districts, all lead by sex workers. One of their key strategies is to shed the stigma attached to sex workers and make them socially acceptable. Since sex work is banned in Nepal they officially position themselves as an organisation promoting the rights and voices of marginalised women and orphan girls, but their main target group are women working in the entertainment sector.

Dhakal emphasises that women who work in the entertainment sector have to internalise the fact that they are not looked at as good women in the eyes of society. However association with an organisation helps because it enhances their image in the society. They earn respect because they are more visible due to their participation in campaigns like violence against women. So other women come to them for help when they have problems. This way there is a social acceptance. She points out that social 
acceptance gives them negotiating power with clients. In most cases this increased bargaining power is the most that can be hoped for. She told us; "due to economic realities of Nepal, it is not practical to tell a woman to stop sex work because she has to feed her family, but when she is educated, made aware of risks and is a part of a network seen to be doing social work it has a positive impact".

In the context of the positive deviancy framework, these actors emerge from difficult situations with a determination to change things for themselves and their peers. Their uncommon traits lie in their self-confidence, determination and ability to be resilient. They have been able to absorb and learn from training programmes, actively participate in social campaigns targeted on women like them and fight through discrimination and stigma. They were able to redefine their position in society as activists, learn management skills to manage organisations and engage in dialogues with donor agencies and the government. Shova Dangal of SWAN says her success is appreciated by people in her village; when she meets young girls working in this sector, she gives her own example which inspires them, they look up to her as a sister.

The social deviancy framework in the context of this research needs to be expanded to analyse the different dimensions. Applying the social ecology to our data we can see that the creation of leaders who can act as critical role models pushing for change certain enabling dimensions need to be in place. The existence of associations with training programmes that help to provoke trigger moments that motivate women into becoming change agents is a core element of the ecology needed to empower women. In the next sector we look at the importance of these programmes linking into peer networks in order to maintain a sustainable environment in which social change can happen.

\section{The role of peer network in the exercising of agency and building resilience}

Understanding how women are able to maintain such high levels of self-confidence and self-esteem whilst also confronted with ongoing harassment, physical and psychological violence at first appears a contradiction. However, in conversation, it is clear that women draw on the resource found in each other. When asked "how do you cope with the constant harassment from your client?" one participant replied; "we talk to each other, we off load our troubles and make fun of our clients". When asked if they feel supported by a wider enabling environment, a common response across the group; "we know we have Menuka and Raksha Nepal, we can go to her and she will listen, provide us with shelter if we need it". The credit scheme has also been critical in supporting the women in projecting forward in their lives and imagining different, safer ways of making money. Those women who now run their own businesses talk about the freedom and relief they feel now because "I am in control of my own destiny, I don't have to put up with abuse in the same way as before". Research that identifies the importance of the social capital generated through peer networks also highlights how invisible it is often even to NGOs and donors committed to removing gender inequalities (Keck and Sikkink, 1998; Sternbach et al., 1992; Weldon, 2006).

Macro secondary quantitative research conducted by Htun and Weldom (2012, p.553) argues that autonomous women's organisation working to end violence is critically important. They list three reasons why women's autonomous organising is so important. Firstly, "women organising as women generate social knowledge about 
women's position as a group in society" [see also Mansbridge (1995) Mansbridge and Morris (2001), Weldon (2011) and Young (2000). The specific contextual understanding of violence that emerges from these groupings is the critical mass needed to direct action toward the relevance entry points in order to bring transformation. These entry points cannot be assumed to be the same for all groupings even within the same cultural context. Secondly, ending VAW requires a shift in the unequal gender structures underpinning societies across the globe. This restructuring will not happen within pre-existing political institutions or parties where the 'gender issue' may struggle to make it onto the agenda in any sustained way. All too often, as Htun and Weldon (2012) point out, VAW is marginalised from public debate. Autonomous organisations committed and focused on ending VAW are the only realistic hope. Thirdly, women's organisations represent safe spaces within which women are able to vent their frustrations at their marginalisation and vulnerabilities seek support and strategise collectively or individually. Organisations that rest within state structures do not represent 'safety' as they fall within the institutional eyes and ears of government that women rightly do not feel always serves to protect and support them. A number of key messages emerge from the research summarised here that resonates with the data we collected from entertainment workers in Nepal. Work is vital for women and has an incredibly important empowering affect raising self-esteem. The informal entertainment sector, however, does not represent a safe space for women. That said by organising together some obstacles can be overcome. Resilience to violence at work is navigated through peer networks and supportive local organisations. Ending the violence that entertainment workers suffer at the hands of their clients is more challenging and we can see the importance of specific figures who work to support women in reflecting on the abuse they suffer. Engagement with organisations that are free to act against violence unconstrained by differing and conflicting political agendas are critical.

\section{Conclusions}

Returning to our original argument, ending the violence women suffer as a result of working in the entertainment sector, and indeed increasing other financially viable options available, will not be achieved through one single entry point but rather it requires a multi layered approach. The ecology of the violence embedded in the entertainment sector is such that it is sustained by outer normalised views that women who work in this sector deserve to suffer. Whilst the demand for sex work increases in Nepal the women who take on these roles continue to be stigmatised. The women who work in the entertainment sector are not defined by their stigmatisation. The high levels of self-esteem are clear but it is also the result of the support received through belonging to strong caring peer networks. The women we spoke to are vocal in rejecting the violence they suffer but are willing to endure it until viable alternatives to income generation are possible. Programming to end VAW needs to reflect the complex and diverse ecology facing different groups of women. As we stated there exists and inner and outer ecology. The existence of local women's organisations committed to campaigning and advocacy on behalf of women in the sector coupled with strong peer networks means entertainment workers have around them a level of emotional and financial security. Transnational feminist ideals are now beginning to shape the policy 
discourse of global institutions. Donors have directed resources towards organisations committed to helping women in this precarious sector. Violence is on the agenda arguably in a more visible way than ever before. However, in order to be effective changes need to be made in what we term the outer ecology. Government must make and see through on commitments to the implementation of legalisation and justice mechanism to promote women's rights and punish perpetrators. For women in the informal entertainment industry this becomes even more complex given that their clients are the very professionals whose support is needed if transformation is to be achieved.

In Nepal there is optimism. The 2015 constitution enshrines a commitment to gender equality widely regarded as a major step in the promotion and achievement of women's rights. This is reflected in a national 'gender equality and social inclusion framework' (GESI) launched in 2017 and designed to support the achievement of this constitutional goal. The framework seeks to support the coordination of all stakeholders and donors in such a way that efforts and energies are effectively utilised for the purpose of improving the lives of the marginalised. The framework advocates working across levels including the district network of local government. However, if the GESI framework is to really bring about the much-needed structural changes in Nepal it must ensure that the experiences of the most marginalised and vulnerable are heard and responded to. These voices are best captured through and within networks and organisations committed to supporting them. These spaces also contain collective women's knowledge and should be seen as a resource to guide and the path towards ending VAW.

\section{References}

Aguilar, D. (2000) 'Questionable claims: colonialism redux, feminist style', Race \& Class, Vol. 41, No. 3, pp.1-12.

Anker, R., Chernyshev, I., Egger, P., Mehran, F. and Ritter, J. (2003) 'Measuring decent work with statistical indicators', International Labour Review, Vol. 142, No. 2.

Barton, B. (2002) 'Dancing on the mobius strip', Gender and Society, Vol. 16, No. 5, pp.585-602.

Basnyat, I. and Joyti Dutta, M. (2012) 'Reframing motherhood through the culture-centered approach: articulations of agency among young Nepalese women', Health Communication, Vol. 27, No. 3, pp.273-283.

Basu, A. and Dutta, M. (2008) 'Participatory change in a campaign led by sex workers: connecting resistance to action-oriented agency', Qualitative Health Research, Vol. 18, No. 1, pp.106-119.

Boyle, K. (2010) 'Selling the selling of sex: secret diary of a call girl on screen', Feminist Media Studies, Vol. 10, No. 1, pp.113-116.

Busza, J. (2004) 'Sex work and migration: the dangers of oversimplification, a case study of Vietnamese women in Cambodia', Health and Human Rights: an International Journal, Vol. 7, pp.231-249.

Caviglia, L. (2017) Sex Work in Nepal: The Making and Unmaking of a Category, South Asia ed., Routledge, London and New York.

Chapkis, W. (1997) Live Sex Acts: Women Performing Erotic Labor, Routledge, New York.

Church, S., Henderson, M., Barnard, M. and Hart, G. (2001) 'Violence by clients towards female prostitutes in different work settings: questionnaire survey', British Medical Journal, Vol. 322, No. 7285, pp.524-525.

Coy, M. (2009) 'This body which is not mine: the notion of the habitbody, prostitution and (dis)embodiment', Feminist Theory, Vol. 10, No. 1, pp.61-75. 
Coy, M., Wakeling, J. and Garner, M. (2011) 'Selling sex sells: representations of prostitution and the sex industry in sexualised popular culture as symbolic violence', Women's Studies International Forum, Vol. 34, pp.441-448.

Department for International Development (DFID) (2012) A Guidance Note: A Theory of Change for Tackling Violence against Women and Girls, DFID Publication.

Deshotels, T. and Forsyth, C.J. (2006) 'Strategic flirting and the emotional tab of exotic flirting', Deviant Behavior, Vol. 27, No. 2, pp.223-241

Ditmore, M. (2014) 'Caught between the tiger and the crocodile: Cambodian sex workers' experiences of structural and physical violence', Studies in Gender and Sexuality, Vol. 15, No. 1, pp.22-31.

Dudash, T. (1997) 'Peepshow feminism', in Nagle, J. (Ed.): Whores and other Feminists, Routledge, New York.

Dworkin, A. (1981) Pornography: Men Possessing Women, Putnam, New York.

Dworkin, A. (1993) 'Prostitution and male supremacy', Michigan Journal of Gender and Law, Vol. 1, No. 1, pp.1-12.

Eaves, E. (2002) Bare: On Women, Dancing, Sex, and Power, Alfred A. Knopf, New York.

Farley, M., Cotton, A., Lynne, J., Zumbeck, S., Spiwak, F., Reyes, M., Alvarez, D. and Sezgin, U. (2003) 'Prostitution and trafficking in 9 countries: update on violence and posttraumatic stress disorder', Journal of Trauma Practice, Vol. 2, Nos. 3/4, pp.33-74.

Friedman, S., Matthew, R., Herington, J. and van de Fliert, E. (2017) 'Positive deviance in theory and practice: a conceptual review', Deviant Behavior, Vol. 39, No. 5, pp.664-678, DOI.

Htun, M. and Weldon, L. (2012) 'The civic origins of progressive policy change: combatting violence against women in global perspective, 1975-2005', American Political Science Review, Vol. 106, No. 3, pp.548-569.

Jeffreys, S. (1997) The Idea of Prostitution, Spinifex, Melbourne, Australia.

Jenkins, R. (1992) Pierre Bourdieu, Routledge, London.

Kabeer, N. (2003) Gender Mainstreaming in Poverty Eradication and the MDGS, Commonwealth Secretariat.

Kabeer, N. (2012) Women's Economic Empowerment and Inclusive Growth: Labour Markets and Enterprise Development, SIG Working Paper.

Kaufman, M., Harman, J., Menger, L. and Shrestha, D. (2016) 'Understanding the experiences and needs of female commercial sex workers in Kathmandu, Nepal', Health Care for Women International, Vol. 37, No. 8, pp.872-888.

Keck, M. and Sikkink, K. (1998) Activists beyond Borders, Cornell University Press, Ithaca, NY.

Klugman, J., Hanmer, L., Twigg, S., Hasan, T., McCleary-Sills, J. and Santamaria, J. (2014) Voice and Agency: Empowering Women and Girls for Shared Prosperity, World Bank Group, Washington, DC.

Liechty, M. (2005) 'Carnal economies: the commodification of food and sex in Kathmandu', Cultural Anthropology, Vol. 20, No. 1.

Liechty, M. (2010) Out Here in Kathmandu: Modernity on the Global Periphery, Martin Chautari Press, Kathmandu.

MacKinnon, C.A. (1987) Feminism Unmodified: Discourses on Life and Law, Harvard University Press, Cambridge, MA.

MacKinnon, C.A. (1989) Toward a Feminist Theory of the State, Harvard University Press, Cambridge, MA.

MacKinnon, C.A. (1993) 'Prostitution and civil rights', Michigan Journal of Gender \& Law, Vol. 1, No, 1, pp.13-31.

Mansbridge, J. (1995) 'What is the feminist movement?', in Ferree, M.M. and Martin, P.Y. (Eds.): Feminist Organizations: Harvest of the New Women's Movement, pp.27-34, Temple University Press, Philadelphia. 
Mansbridge, J. and Morris, A. (2001) Oppositional Consciousness: the Subjective Roots of Social Protest, Chicago University Press, Chicago.

Marsh, R.D., Schroeder, D.G., Dearden, K.A., Sternin, J. and Sternin, M. (2004) 'The power of positive deviance', $B M J$, Vol. 329, pp.1177-1179.

Monto, M. (2014) 'Prostitution, sex work, and violence: lessons from the Cambodian context', Studies in Gender and Sexuality, Vol. 15, pp.73-84.

Murthy, L. and Seshu, M.S. (2013) The Business of Sex, Zubaan, New Delhi.

O'Connell Davidson, J. (2002) 'The rights and wrongs of prostitution', Hypatia, Vol. 17, No. 2, pp.84-98.

O'Connell Davidson, J. (2002) 'The rights and wrongs of prostitution', Hypatia, Vol. 17, No. 2, pp.84-98.

O'Connor, M. and Healy, G. (2006) The Links Between Prostitution and Sex Trafficking: A Briefing Handbook. Coalition against Trafficking in Women (CATW) \& European Women's Lobby (EWL) [online] http://www.catwinternational.org/Content/Images/Article/ 175/attachment.pdf.

Raphael, J. and Shapiro, D.L. (2004) 'Violence in indoor and outdoor prostitution venues', Violence against Women, Vol. 10, No. 2, pp.126-139.

Sternbach, N., Navarro-Aranguren, M., Chuchryk, P. and Alvarez, S.E. (1992) 'Feminisms in Latin America: from Bogota to San Bernardo', Signs: A Journal of Women in Culture and Society, Vol. 17, No. 3, pp.393-434.

Weitzer, R. (2005) 'New directions in research on prostitution', Crime, Law, and Social Change, Vol. 43, Nos. 4-5, pp.211-235.

Weitzer, R. (2010) Sex for Sale: Prostitution, Pornography and the Sex Industry, 2nd ed., Routledge, New York.

Weldon, S.L. (2006) 'Inclusion, solidarity and social movements: the global movement on gender violence', Perspectives on Politics, Vol. 4, No. 1, pp.55-74.

Weldon, S.L. (2011) When Protest Makes Policy: How Social Movements Represent Disadvantaged Groups, University of Michigan Press, Ann Arbor.

Young, I.M. (2000) Inclusion and Democracy. Series in Political Theory, Oxford University Press, New York.

Yuval-Davis, N. (2006) 'Intersectionality and feminist politics', European Journal of Women's Studies, Vol. 13, No. 3, pp.193-209. 